\title{
The application of outsourcing decision-making methods in a logistics context in South Africa
}

\begin{abstract}
Authors:
Naomi Bloem ${ }^{1,2}$

Wilna L. Bean ${ }^{2}$

Affiliations:

${ }^{1}$ Clover Industries Limited,

Roodepoort, South Africa

${ }^{2}$ Department of Industrial and Systems Engineering,

University of Pretoria, South Africa

Correspondence to:

Naomi Bloem

Email:

naomi.bloem@clover.co.za

Postal address:

PO Box 6161, Weltevreden

Park 1715, South Africa

Dates:

Received: 08 Dec. 2014

Accepted: 30 Apr. 2015

Published: 28 July 2015

How to cite this article: Bloem, N. \& Bean, W.L., 2015, 'The application of outsourcing decision-making methods in a logistics context in South Africa', Journal of Transport and Supply Chain Management 9(1), Art. \#168, 14 pages. http://dx.doi. org/10.4102/jtscm.v9i1.168

\section{Copyright:}

(C) 2015. The Authors.

Licensee: AOSIS

OpenJournals. This work is

licensed under the Creative

Commons Attribution

License.
\end{abstract}

Read online:
Background: Companies have often relinquished the control of important business functions to outside suppliers for the sake of short-term savings and because of the lack of use of proper decision-making methods within the business.

Objectives: This article identified three methods of decision-making and applied it to a logistics outsourcing problem. The logistics outsourcing problem consisted of a make-or-buy decision as well as a supplier selection process. The purpose of the study was to determine the most suitable method in the case of logistics outsourcing.

Method: The decision-making methods were applied to a South African case study within the fast moving consumer goods (FMCG) industry. The logistics functions considered in the case study included secondary distribution and warehousing of finished goods. Each method considered the same evaluation criteria and the results were analysed and compared.

Results: Each method produced different results to the logistics outsourcing problem. The method developed by Platts, Probert and Canez (2000) suggested that the logistics functions be insourced. The decision tree method suggested outsourcing both functions, with a unit rate cost model. The results from the linear programming (LP) method indicated that the secondary distribution function should be insourced and the warehousing function outsourced, with a fixed and variable cost model pending further analysis of the demand trends.

Conclusion: The study provides empirical evidence that proven outsourcing decision-making methods, such as the method developed by Platts et al. (2000), the LP method and the decision tree method traditionally applied to a manufacturing outsourcing decision problem, can be adapted and applied to a logistics outsourcing decision problem of a South African FMCG company.

\section{Introduction}

'Today's complex global business environment - with its rapidly advancing technologies, emerging world markets, and vastly extended supply chains - places increasingly critical decision-making demands on logistics professionals' (Fitzgerald 2007:1). McIvor and Humphreys (2000) suggest that in a make-or-buy decision-making context, too many companies have relinquished core business functions to outside suppliers, mistakenly identifying these functions as cost centres. Sangam (2013) postulates that outsourcing logistics functions is one of the managerial decisions often made without suitable situational investigation, evaluation and analysis, and often arises from companies seeking a quick and easy way to cut costs in tough economic situations.

\section{Problem statement}

It has not yet been determined if proven make-or-buy decision-making methods can be applied successfully in a logistics context. A need exists for a method that will aid middle management to better structure the logistics outsourcing decision problem. The method should address the operational complexities involved, compare different logistics outsourcing options on the same basis, quantify risks and rewards, and keep the company's core competency and long-term logistics strategy in mind.

\section{Research objectives}

The objective of this study was to apply proven decision-making methods to a logistics outsourcing decision problem in a South African context, in order to make recommendations to tactical decision makers about the use of these methods when executing company logistics strategies. The secondary research objectives were the following:

- Compare how the proven methods incorporate evaluation criteria such as logistics costs, risk, logistics strategy, service provider fit, the degree of market growth and service levels. 
- Determine how the outcome of each proven decisionmaking method compares to that of the others.

- Draw a conclusion as to the most appropriate method to use in the logistics outsourcing context.

The make-or-buy decision and supplier selection processes were combined in this study, as these processes are not mutually exclusive. Moreover, the lack of proper service providers may force a company to insource even though the evaluation criteria for outsourcing have been met.

\section{Research approach}

Various make-or-buy and supplier selection methods were identified through a thorough literature study of outsourcing practices, in both the logistics and manufacturing sectors. The criteria for decision-making methods that are practically implementable included the following: the methods should be based on sound scientific or statistical inference; methods should minimise the risk of biased decision-making; and uncertainty, multiple attributes and multiple objectives should be incorporated. Three proven decision-making methods that met the criteria were selected. The chosen decision-making methods were applied to a South African case study company, analysed and compared. Subsequently, the most appropriate method in a logistics outsourcing context of the fast-moving consumer goods (FMCG) industry in South Africa was proposed.

\section{Literature review \\ The make-or-buy decision}

When a company outsources a business function, a buy decision is made, as opposed to a make decision when the function is performed in-house. Logistics functions that are popularly outsourced include warehousing, secondary distribution of goods, primary logistics, reverse logistics and logistics planning (Razzaque \& Sheng 1998). Hsiao et al. (2010) describe the instances when a buy decision may be made: when logistics activities do not form part of a central function to the company; where poor in-house information technology (IT) capabilities exist; when it is critical for a company to grow market relationships in order to increase customer footprint and market share and when a substantial cost-benefit exists and no unique risk is presented. Moses and Åhlström (2008) add that a company is likely to outsource if there is proof of a short-term cost saving or marginal cost-benefit in entering the agreement. Moschuris (2008) lists external environmental triggers, such as rising price competition, as reasons to reduce costs and therefore outsource.

There are many reasons why companies may decide not to outsource, but rather perform logistics operations in-house. One such reason is the high switching cost of implementing outsourcing (Hsiao et al. 2010). Another reason to insource, identified by Gadde and Hulthén (2009) and Rahman (2011), is a possible loss of management control. In addition, Gadde and Hulthén (2009) have identified the lack of advanced IT to integrate the supply chain, information loss, proper in-house service provider management, misalignment between service provider and buyer, and management distrust of third-party logistics providers (3PLs) as reasons for insourcing.

\section{Proven decision-making methods}

McIvor and Humphreys (2000) state that one of the key problems encountered by companies during the make-orbuy decision is the lack of a formal method for evaluating the decision. Companies tend to focus on short-term overhead costs and not on the long-term growth view (McIvor \& Humphreys 2000). In addition, they mention that many companies find themselves outsourcing to achieve shortterm savings or owing to an inherited position. Wan et al. (2015) state that ineffective outsourcing activities can lead to unexpected risk and loss of core competencies and capabilities. Companies may make so many decisions focused on the short term that these decisions become part of a fully integrated long-term strategy that is not flexible. Literature on proven decision-making methods in the case of outsourcing logistics or manufacturing functions refers to the following methods: case-based reasoning and transaction cost analysis (McIvor \& Humphreys 2000); the Von NeumannMorgenstern concept of utility applied to decision trees (Winston 2004); a method developed by Platts et al. (2000) and linear programming (Guneri, Yucel \& Ayyildiz 2009; Wan et al. 2015; Winston 2004).

\section{Case-based reasoning}

McIvor and Humphreys (2000) investigated the use of casebased reasoning for making a decision regarding outsourcing in a manufacturing context. Case-based reasoning compares historical results obtained from dealing with suppliers with the case in question. The case refers to an opportunity to outsource. Historical results are kept in a data repository, and include cost, quality, service provider characteristics and any historical issues with the supplier. This method proves to be very effective in the manufacturing industry, where the manufacturing of certain parts can be outsourced to multiple suppliers. Products are easily manufactured, requirements generally stay constant and products can be provided by a range of suppliers on the market. The duration of these contracts can be limited to a few batches or stretch over years.

In contrast, outsourcing a logistics function is less easy, because the expertise needed is driven by product, network and process complexities. Customer requirements are ever changing and driven by the end customer's expectations. Logistics contract periods tend to be longer than those of manufacturing contracts and the switching costs associated with changing lead service providers (LSPs) are much higher than those associated with changing manufacturing suppliers. As a result, it would be very challenging to build a database for the purpose of service provider comparison. An important advantage of using case-based reasoning is that 
historical performance achievements are taken into account when making the supplier selection or even the make-orbuy decision. Case-based reasoning is capable of evaluating suppliers' capabilities based on technical and organisational profiles (Arvelos 2014). Suppliers are rated based on previous experience with the supplier or by verification of a supplier reference.

\section{Multiple criteria decision-making}

Another technique mentioned by McIvor and Humphreys (2000) is that of multiple criteria decision-making (MCDM), which considers multiple attributes in respect of multiple client objectives. Such attributes can include cost, service levels, lead times, service provider stability and quality of service. Each attribute is assigned a weighting that is obtained from polling industry experts on the importance of the attribute. Suppliers are rated and ranked based on their perceived performance (McIvor \& Humphreys 2000). The use of multiple criteria in a decision-making process is very important for decisions in the logistics outsourcing context, due to the complexity of the logistics solutions, the uncertainty and multiple business objectives associated with the decision.

\section{Decision trees}

Winston (2004) describes the Von Neumann-Morgenstern concept of decision-making under uncertainty. This concept compares events such as lotteries, each having an expected outcome or utility, and takes the probability of multiple outcomes into account. These events can be illustrated in decision trees, which consist of multiple branches that correspond to different alternative events, each with a certain outcome. Based on the decision maker's preference for each expected outcome of an event, the risk aversion of the decision maker can be determined and a recommendation can be made as to how much value the decision maker places on each outcome. This method can be applied to the logistics outsourcing decision problem to determine what each party the customer and the service provider - considers a fair price for the services on offer. This process can ensure that expectations are managed and that a mutual understanding of the value associated with the decision exists.

Decision trees can be used to decompose a large, complex decision problem into several smaller problems (Winston 2004). Each smaller problem consists of multiple objectives to be reached and the decision maker is shown the risk (level of uncertainty) and utility associated with reaching these objectives in each case. Winston (2004) proposes the use of multi-attribute utility functions in decision trees.

Ruiz-Torres and Mahmoodi (2007) used the decision tree method in a manufacturing context to determine the number of suppliers required, whilst considering supplier failure risk and procurement and operational cost savings. This can easily be translated into a logistics context by considering LSP service levels (in full and on time delivery) rather than supplier failure, and logistics costs rather than procurement savings.
The decision tree method offers a decision maker the opportunity to look at multiple alternatives, taking into account multiple decision variables and uncertainty, whilst producing an expected utility.

\section{Platts et al. method}

Platts et al. (2000) propose an encompassing model that considers technology, costs and a strategic framework. They acknowledge that the make-or-buy decision is not a static issue and should be reassessed periodically by measuring in-house and supplier performance. The method views the outsourcing problem as a collection of areas that affect the performance of the function in consideration. Each area consists of a group of functions which can be quantified.

Areas and factors are rated to determine supplier and in-house capabilities, which are assigned weightings based on their importance within the process. The results give a definitive answer to the make-or-buy question. A robustness test is performed by testing the sensitivity of each area to a change in weighting. Once the process has been determined to be robust, a final decision can be made (Platts et al. 2000).

This method has been tested practically (Arvelos 2014) and has a periodic review component that the other methods lack. Logistics change at the same pace that consumer demand changes, and a decision made today might not be feasible tomorrow. The method reduces the risk of biased decisionmaking, as it requires a large project team to assign weightings and ratings to various decision variables. Arvelos (2014) suggests that the definitions of these ratings be made clearer in order to improve the model and that a costing exercise be developed to support the ratings assigned to the costs area. It is a multi-attribute decision-making method that is key to successful logistics outsourcing decisions and comparable to case-based reasoning and the decision tree method.

\section{Linear programming}

Winston (2004) reports that linear programming (LP) is a tool used to solve optimisation problems. Linear programming consists of single-objective or multiple-objective functions that are optimised (maximised or minimised) subject to certain constraints placed on the model. Guneri et al. (2009) propose an integrated method consisting of fuzzy logic and an LP model. The model is designed to consider qualitative and quantitative attributes to make a supplier selection decision in the manufacturing context. The model produces the optimum quantities to assign to each supplier, whilst maximising the total value of purchasing (TVP), which consists of relationship closeness, reputation and position in the industry, performance history, and conflict resolution and delivery capability. Total value of purchasing is maximised subject to the constraints imposed by demand, product quality and budget.

The LP method offers the decision maker the option of selecting not only a single supplier but multiple suppliers, without overcomplicating or increasing the duration of the 
decision-making process. Multiple attributes and objectives can be incorporated in this method, which provides a definitive answer based on scientific inference.

\section{Research method}

Empirical research performed sought to determine whether proven outsourcing decision-making methods could be applied to a logistics outsourcing context in order to make recommendations to the tactical decision makers responsible for the execution of company logistics strategy.

\section{Strategy and research design}

The results of a thorough literature study of various makeor-buy decision-making methods were used as a foundation for comparison of the various decision-making methods available (Guneri et al. 2009; McIvor \& Humphreys 2000; Platts et al. 2000; Ruiz-Torres \& Mahmoodi 2007; Winston 2004). The comparison of various methods provided the authors with a range of methods to choose from to apply in the context of logistics outsourcing.

The decision tree method (Winston 2004), the method developed by Platts et al. (2000) and LP (Guneri et al. 2009) were chosen to apply to a logistics outsourcing decision problem. These methods are based on sound scientific or statistical inference, minimising the risk of biased decisionmaking by incorporating the inputs of multiple stakeholders and service provider references, and taking uncertainty, multiple attributes and multiple objectives into account.

To apply the selected proven decision-making methods successfully to a South African context, a local industry case study was used. The use of a research method such as a case study gave the authors the opportunity to determine whether the various decision-making methods were practical. The case study company manufactures food and beverages for the FMCG industry in South Africa. It has an annual turnover of R7 billion and is considered to be a large enterprise. The company was chosen because it is a large enterprise representing the sector with the largest contribution to the national transport cost in South Africa, as per Statistics South Africa's (2014) Land Transport Survey.

In order for the company to be a good fit for evaluation of the selected methods, it had to have the means either to implement practically an in-house logistics solution or to outsource. Investing in the development of an in-house solution requires a company to have a high level of liquidity or access to investor funds to fund the start-up of such operations. At the time of the study, the case study company had an above acceptable liquidity ratio of 1:7; in addition, the company was listed on the Johannesburg Stock Exchange. In addition to the funds required to insource, the company also had to acquire the right level of expertise and management capabilities to sustain successful in-house operations. The case study company not only exceeded the required level of liquidity and met the in-house expertise requirement, but had recently completed a procurement process for logistics services to potentially realise its logistics strategy of achieving high service levels to end customers at a sustainable cost.

\section{Data collection and analysis}

To study the case study company's logistics functions, strategy and requirements, the research team used semistructured interviews as the primary data collection method. Different employees were interviewed to ensure that multiple perspectives were captured and a detailed understanding of the case was developed. Employees were all knowledgeable in the area of company logistics capabilities, procurement procedure and the strategic direction of the company.

Questions were structured to lead the interviewees through the process of decision-making from the start of the makeor-buy decision process to the point where the actual decision was made. The interviewer led the interviewees through this process without restricting answers to the questions posed and allowed them to elaborate where possible. The case study company gave the research team access to proposal documents from the service providers who had responded to the request for proposal (RFP). The company made historical data, in-house historical logistics performance figures and logistics-related costs available to the research team.

Data used in the study was validated by ensuring that it was the same as the data available to the case study company during the procurement process. A range of follow-up interviews and workshops were held after the data and information provided had been scrutinised. This gave the research team the opportunity to collect additional information needed to apply the decision-making methods.

The methods were each applied to the logistics outsourcing decision of the case study company and the results were analysed to interpret the outcome of the decision. The degree to which the methods incorporated evaluation criteria such as logistics costs, risk, logistics strategy, service provider fit, the degree of market growth and service levels were compared by further investigation of the results of each method. A recommendation was made on the practical application of the methods.

\section{Analysis Platts et al. (2000) method}

The method of decision-making developed by Platts et al. (2000) combines technological considerations, a cost model and the strategic company framework into a single structured decision-making model to directly answer the make-or-buy decision. This method, originally developed and tested for manufacturing outsourcing, consists of three phases: the preparation phase, the data collection phase and the analysis and results phase. During the preparation phase the project team, which consists of different employees within 
TABLE 1: Area weightings.

\begin{tabular}{lc}
\hline Description & Weight (\%) \\
\hline Costs & 37 \\
Service & 27 \\
Technology and process & 18 \\
Auxiliary functions & 18 \\
\hline
\end{tabular}

TABLE 2: Factor weightings.

\begin{tabular}{llc}
\hline Area & Factor & Weighting (\%) \\
\hline Costs & Cost of logistics activity & 50 \\
& Economies of scale & 50 \\
Service & Market footprint & 30 \\
& Risk mitigation & 30 \\
& Service levels & 30 \\
& Operational efficiency & 10 \\
Technology and process & Technological advancement & 33 \\
& Technical expertise & 33 \\
& Process capabilities & 33 \\
Auxiliary functions & Advanced analytics & 17 \\
& Project management capabilities & 33 \\
& Financial stability & 50 \\
\hline
\end{tabular}

the company, is created and briefed on the decision to be made. The data collection phase comprises the identification of classes, named 'areas' by Platts et al. (2000). These classes or areas are typically areas of concern directly attributable to the function to be outsourced, such as costs and service levels. Each area consists of factors. In the case of the costs area, the factors might be cost of operations, cost of switching and economies of scale. The project team assigns scores to the factors within the areas and compare in-house and supplier scores to produce an answer to the make-or-buy decision during the analysis and results phase.

In the case study, the areas for the decision to make-orbuy logistics services were identified as cost, service levels, technology and process functions, and auxiliary functions (Table 1).

The costs area factors identified by representatives from the company included logistics costs and economies of scale. The service level area consisted of market footprint, risk mitigation, service levels and operational efficiency. The technology and process area consisted of technological advancement, technical expertise and process capabilities. Auxiliary functions included advanced analytics, project management capabilities and financial stability of the service provider.

Middle to top management representatives from the company assigned weightings to the areas, after which the average from the weighting assigned by each individual was determined. Higher management weightings were not favoured, as each level of management represents a different perspective towards the decision to be made.
The factors in each area were assigned weightings in a similar fashion as the areas (Table 2).

Once each area and factor had been assigned a weighting, the company representatives assigned a rating per factor for in-house capabilities as well as supplier capabilities. A rating out of four, where one is the lowest rating and four the highest, was assigned by each individual, and the average of all the individual ratings multiplied by the weighting per factor became the score for the particular factor for either in-house capabilities or supplier capabilities (Table 3).

During the analysis and results phase, the score per factor per area was summed to produce a score per area, which was then multiplied by the weighting per area to obtain a total score. Likewise, in Table 3, the in-house score for the costs of the logistics activity function was obtained by multiplying the weighting of $50 \%$ with the rating of four, which resulted in an in-house score of two. To obtain the in-house score for the costs area, the scores for the functions of the cost of logistics (two) and economies of scale (one) were added to produce a score of three. The in-house total score was calculated by multiplying the score per area by the corresponding weighting per area to produce a total in-house score of 2.66 (Table 4).

The difference or gap between the in-house score and that of the supplier was analysed. A negative gap represents an area in which the company could improve its in-house capabilities. Table 4 indicates that the company could improve its capabilities in the technology and process area. A positive gap indicates that the in-house capabilities exceed that of the supplier. If the total in-house score is higher than that of the supplier, it indicates that the 'make' decision should have been made.

To test the robustness of the 'make' decision, a sensitivity analysis for each area was performed and the total in-house and supplier score per iteration calculated (Figure 1). The sensitivity analysis requires the weighting of the area in question to be changed to determine the impact it has on the total score. The weighting of the other areas was changed, maintaining the original proportions. If the area's weight is changed to zero, it represents the case where the area is not taken into account when making the decision. Where the lines cross, the decision is sensitive to changes in the weighting of the area.

The break-even point is very close to zero, which means that the decision is robust in the costs area.

When considering the service area sensitivity (Figure 2), a break-even point exists at $60 \%$ weighting. This shows that, should service levels become more important to the company and the weighting increase in this area, the decision would

TABLE 3: Scoring

\begin{tabular}{llcccc}
\hline Area & Factor & Weighting (\%) & In-house rating & Supplier rating & Supplier score \\
\hline Costs & Cost of logistics activity & 50 & 4 & 3 & 2.00 \\
& Economies of scale & 50 & 2 & 2 & 1.50 \\
& & & 1.00 & 200 \\
\hline
\end{tabular}


TABLE 4: Results.

\begin{tabular}{lcccc}
\hline Area & Weight (\%) & Internal score & Supplier score & Gap \\
\hline Costs & 37 & 3.00 & 2.50 & 0.50 \\
Service & 27 & 2.40 & 2.60 & -0.20 \\
$\begin{array}{l}\text { Technology and } \\
\text { process }\end{array}$ & 18 & 2.00 & 2.33 & -0.33 \\
Auxiliary functions & 18 & 3.00 & 2.50 & 0.50 \\
\hline Total & $\mathbf{1 0 0}$ & $\mathbf{2 . 6 6}$ & $\mathbf{2 . 5 0}$ & $\mathbf{0 . 1 6}$ \\
\hline
\end{tabular}

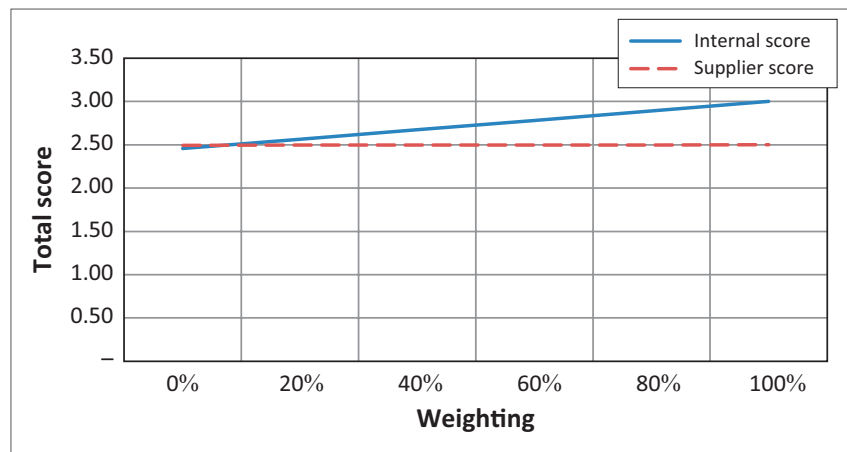

FIGURE 1: Costs area sensitivity.

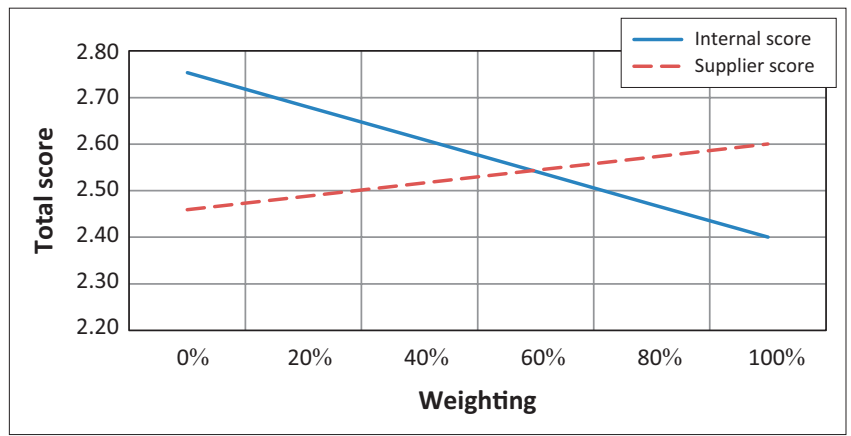

FIGURE 2: Service area sensitivity.

swing towards the supplier. There is, however, a sufficient gap between the assigned weighting of $27 \%$ and the breakeven point. The decision is thus slightly sensitive to service levels, which should be reviewed periodically to ensure that the right make-or-buy decision was made, but at this stage it was still in favour of insourcing.

Similar graphs were created for the technology and process and auxiliary functions areas. The technology and process area sensitivity analysis showed a break-even point at 50\%, which presents the project team with a gap of $32 \%$ between the original weighting of $18 \%$ and the break-even point. This is three times the original weighting, but the probability of the area's becoming three times more important relative to the other areas is small, thus the decision is not sensitive in the technology and process area. The auxiliary functions area sensitivity analysis showed similar results to that in Figure 1 and did not indicate sensitivity in this area.

\section{Decision trees}

A decision tree is a method used to make decisions by taking possible outcomes stemming from the decision's alternatives into account, associating a probability of occurrence and a utility earned to each outcome. The method consists of a tree fallen on its side. The decision forks represent the alternative options, the uncertainty forks represent the different outcomes from each option and a utility function in the leaves of the tree could represent a payback on an investment decision or a cost incurred on an expense related to the decision (Savage 2003).

In a logistics outsourcing decision-making problem, the decision tree can be structured in such a way that it takes into account all the important factors identified by the customer's long-term logistics strategy, appetite for risk, cost sensitivity and service level requirements, to name just a few. Each alternative, or branch, represents an option to either insource or outsource by means of different outsourcing models. Factors that affect the outcome of each alternative or branch, such as demand variability and reaching target service levels, can be modelled by adding uncertainty forks to each branch, representing the probability that demand and service levels will exceed, elude or meet expectations and adding the associated utility to each outcome.

The probabilities of outcomes pertaining to demand activity realising can be closely modelled by completing a statistical analysis of historical sales data. The same probabilities of reaching service level targets can be determined by analysing historical in-house performance or contacting the LSP references. The utility associated with each outcome can be modelled by associating the cost of adding capacity to deal with increased demand or by calculating the opportunity cost due to lost sales as a result of service levels not achieved.

The parameters of the logistics operations in question were set using the information retrieved from the interviews held with representatives from the case study company, the responses to the RFP, in-house performance results and historical data.

\section{Modelling logistics activities}

A data model was built to determine the daily resource requirements to serve the market by either performing the function in-house or by outsourcing to an LSP. The model was based on the premise that demand activity drives resource requirements and incurs costs. Actual in-house performance results were used to determine the resource requirements in the case of the in-house scenario and industry benchmarks, derived from tender document assumption lists and results, in the case of the LSPs.

A thorough analysis of historical sales figures indicated that demand activity contains multiple dimensions that drive costs in different areas of the logistics operation. Such dimensions include volume such as weight or volumetric mass; complexity such as the variety of products to be handled; the number of handling units such as cases; sales value and the number of delivery points to be served. Different dimensions drive the costs of different logistics functions. For example, secondary distribution cost in a time-constrained network is 
affected by the number of delivery points to serve. The fleet size is directly proportional to the number of deliveries a single vehicle can accomplish in a day. In a time-constrained network, a vehicle's time capacity, that is, the time allotted to do deliveries, is reached before the vehicle's payload is reached. Thus, the number of vehicles required is determined by the total number of deliveries for the day. The complexity of the payload, i.e. the number of different products, affects the time a vehicle needs to spend at the end customer's back door sorting the order, which affects the number of deliveries the vehicle can make in a day and determines the fleet size. The allocated volume affects the required vehicle payload or the size of the vehicles required. Larger payload vehicles are more expensive than smaller payload vehicles.

Each dimension in the data was analysed by drawing up a histogram of the data, fitting a distribution and determining whether a normal distribution is a good fit by means of the chi-square goodness of fit test. All variables except complexity were fitted with a normal distribution. No existing distribution could be fitted to the complexity variable, but as the standard deviation for this variable is so small, it was decided to assume a constant value of 114 , which corresponds to the mean. The distribution for drops was fit non-parametrically making use of advanced statistical software. Based on the distributions fitted to each variable, an expected value for each variable could be determined within a certain confidence interval (Table 5).

The expected value $(E[x])$ corresponding to the confidence interval of each variable was then used as base for the logistics solution design. This design included components such as the fleet size required for secondary distribution and the warehouse requirements; staff complement and material handling resources required to perform the receiving; and storing and picking operations within the warehouse. All the design component-related costs such as vehicle cost, warehouse rental, material handling equipment rental and staff complement were combined to obtain the cost of performing the logistics functions in-house.

\section{Modelling logistics costs}

To relate cost to the design component (fleet), for example, we know that the expected number $(E[x])$ of drops affects the in-house secondary distribution solution, which consists of the fleet of vehicles and staff. As a simple example, the expected number of daily deliveries (603) would be divided by the number of drops an in-house vehicle can achieve in a day (6) relative to the volume of the order to determine the

TABLE 5: Confidence intervals for the expected value of each variable.

\begin{tabular}{lllll}
\hline Data dimension & $\mathbf{E}(\mathbf{x})$ & $\mathbf{C l}(\%)$ & $\mathrm{Cl}_{\mathrm{UL}}$ & $\mathbf{C l}_{\mathrm{UL}}$ \\
\hline Volume & 322166 & 95 & 308068 & 336263 \\
Handling units & 48783 & 95 & 46685 & 50881 \\
Sales value & 3336300 & 95 & 3193359 & 3479241 \\
Drops & 603 & 95 & 583 & 623 \\
Complexity & 114 & 95 & 112 & 116 \\
\hline
\end{tabular}

$\mathrm{E}(\mathrm{x})$, expected value; $\mathrm{Cl}$, confidence interval; $\mathrm{Cl}_{\mathrm{U}^{\prime}}$ confidence interval lower limit; $\mathrm{Cl}_{\mathrm{UL}^{\prime}}$ confidence interval upper limit. number of vehicles required or the fleet size (100 vehicles). The fleet size is then multiplied by the cost of a vehicle and staff to obtain the in-house expected costs associated to this particular design component. To assess the secondary distribution cost if the number of drops exceeded or eluded expectations, the confidence interval's upper limit of drops (623) and lower limits of drops (583) were used in the cost calculation instead of the expected value of drops $(E[x])$. In many cases where the expected value of the cost driver is exceeded, additional capacity in the form of daily rented vehicles must then be created, which comes at a premium.

The information obtained from the RFP responses highlighted three different LSP offerings.

Outsourcing with a unit rate cost model: The LSP charges the customer per unit handled for each service offered. A unit can be a case, a pallet or a loose unit of product. Thus, if a LSP were to offer a customer warehousing and secondary distribution services, the cost model would consist of a warehousing rate per case, covering the inbound handling, storage, case picking and outbound handling costs and a rate per case delivered to cover the secondary distribution service.

Outsourcing with a fixed and variable costs model: The service provider charges a fixed monthly fee for warehousing and distribution with a variable rate that is linked to the number of kilometres travelled by the secondary fleet and/ or a rate per unit. Any additional costs incurred, such as overtime and additional staff and vehicles, are recovered from the customer.

Outsourcing with a percentage of sales value charge: The service provider charges the customer a percentage of the sales value of goods sold. In this case, the service provider takes ownership of stock throughout the network.

Each LSP offering was applied to the same level of distribution activity as per the confidence intervals determined for the in-house capability model to determine the resultant logistics costs and documented in the decision tree.

\section{The decision tree model}

A decision tree was developed to show the options facing the case study company in the logistics outsourcing decision. The first decision fork (Figure 3) represents the four choices the customer faces: keeping the logistics functions in-house; outsourcing with a rate per kilogram cost model; outsourcing with a fixed and variable costs model and outsourcing with a percentage of sales value cost model.

The second level of branching (Figure 3) illustrates the first uncertainty fork, which represents the volatility of demand activity and the effect on logistics costs to the case study company within the parameters of the option. Uncertainty forks branching from here indicate different levels of demand activity spread from each option. The top prong indicates 


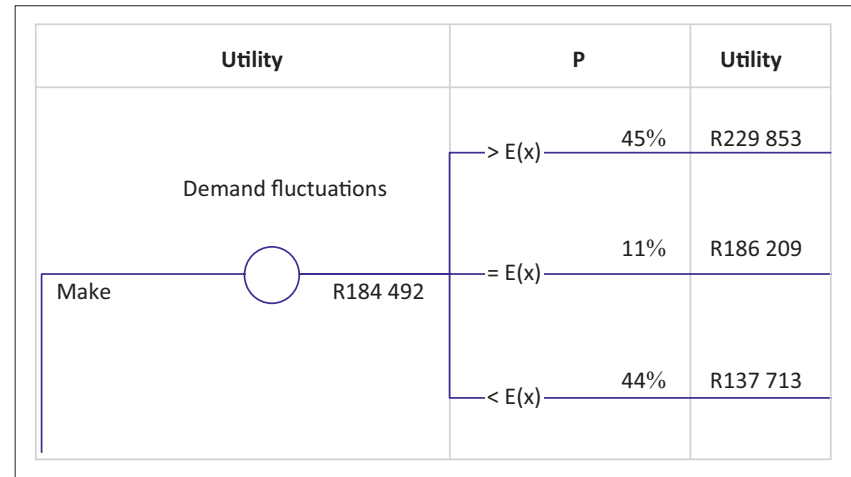

FIGURE 3: First uncertainty fork.

demand activity above the expected (above the upper limit of the $95 \%$ confidence interval); the middle prong represents demand activity within the $95 \%$ confidence interval; and the lowest prong represents demand activity below the expected (below the lower limit of the 95\% confidence interval). Each option facing the case study company was designed to accommodate the expected level of demand activity. Any activity outside the confidence interval will be outside of the normal logistics costs and may indicate a saving or additional cost incurred due to lack of logistics capacity.

The third level of branching or the second uncertainty fork illustrates the resultant service level based on the demand activity fluctuation (Figure 4). The expected service level corresponds to the service level promised by the service provider in the RFP responses and includes the degree to which the orders were delivered in full and on time to the end customer. The probability that the service level will be lower is determined by the service provider's means of dealing with potential demand fluctuations. This was determined by comparing the service provider's means of accessing additional resources, such as additional vehicles and labour, and leveraging economies of scale amongst other operations on a relative basis. A service provider would perform better in this case if it had access to a pool of vehicles, an agreement with a short-term vehicle rental company or other operations with which it could pool the risk of demand fluctuation.
Actual in-house service level trends were used to establish the in-house values. The expected yield from lower than expected service levels corresponds to the opportunity cost lost or value of lost sales, which is determined by using the average value of lost sales per service level percentile from historical data.

The expected utility was determined for each branch by adding the product of the probability of the demand fluctuation and the cost thereof to the product of the probability of service level fluctuations and the loss of sales. As an example, the upper branch (Figure 4) corresponds to a $45 \%$ probability of the demand (Figure 5) being greater than expected, multiplied by the cost (R220 853) incurred to manage the demand spike, and adding the product of the probability $(60 \%)$ that the expected service level will be reached and the opportunity cost of the value of sales loss (R134 916). This results in an expected utility of R184 682 for the particular branch.

The likelihood of occurrence for the same branch can be determined by multiplying the probability of the expected demand $(45 \%)$ and the probability of the service levels making target $(60 \%)$. This results in a likelihood of $27 \%$. The sum of the likelihood of all the branches belonging to an option results in 1 . The maximum likelihood for each option can be determined. The full decision tree is presented in Figure 5. It can be observed that in this case study the branch depicting demand fluctuations eluding expectations and service levels meeting expectations has the highest likelihood of occurrence at $44 \%$.

\section{Linear programming}

A linear programming model was used to determine whether this method could successfully be applied to the logistics outsourcing decision problem of the case study company. The historical data provided by the case study company were used as logistics activity inputs (customer demand, number of deliveries, volume to be picked in the warehouse and delivered, etc.), similar to the decision tree method. The model then optimised the make-or-buy

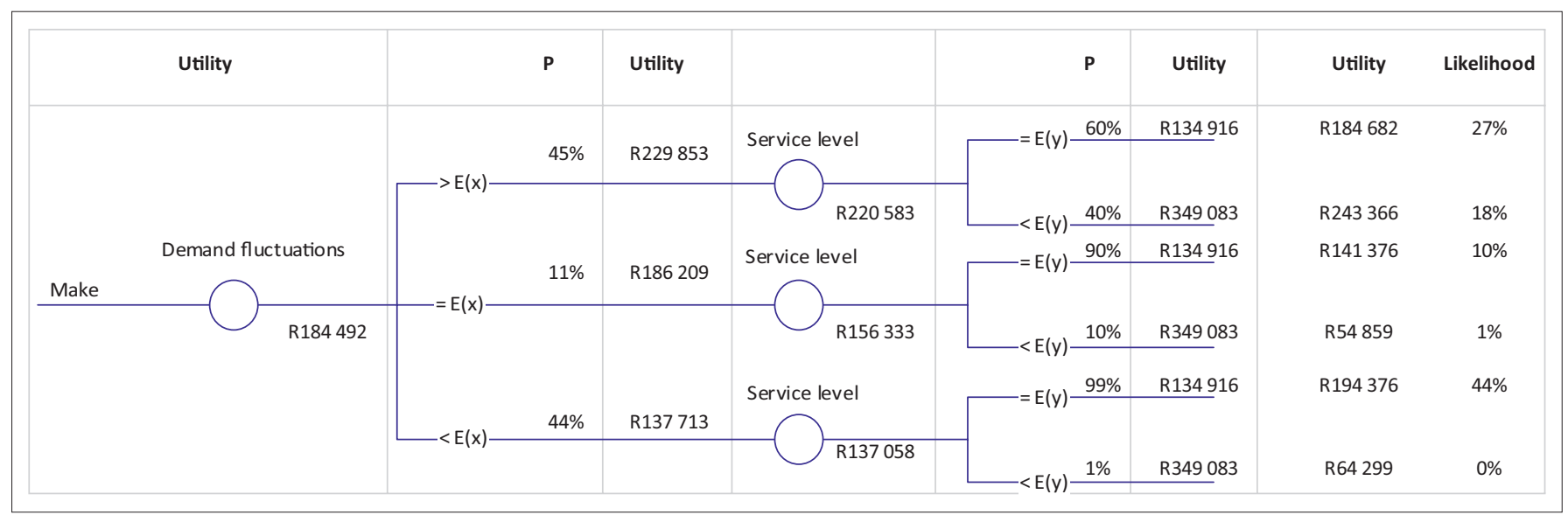

FIGURE 4: Service level uncertainty. 


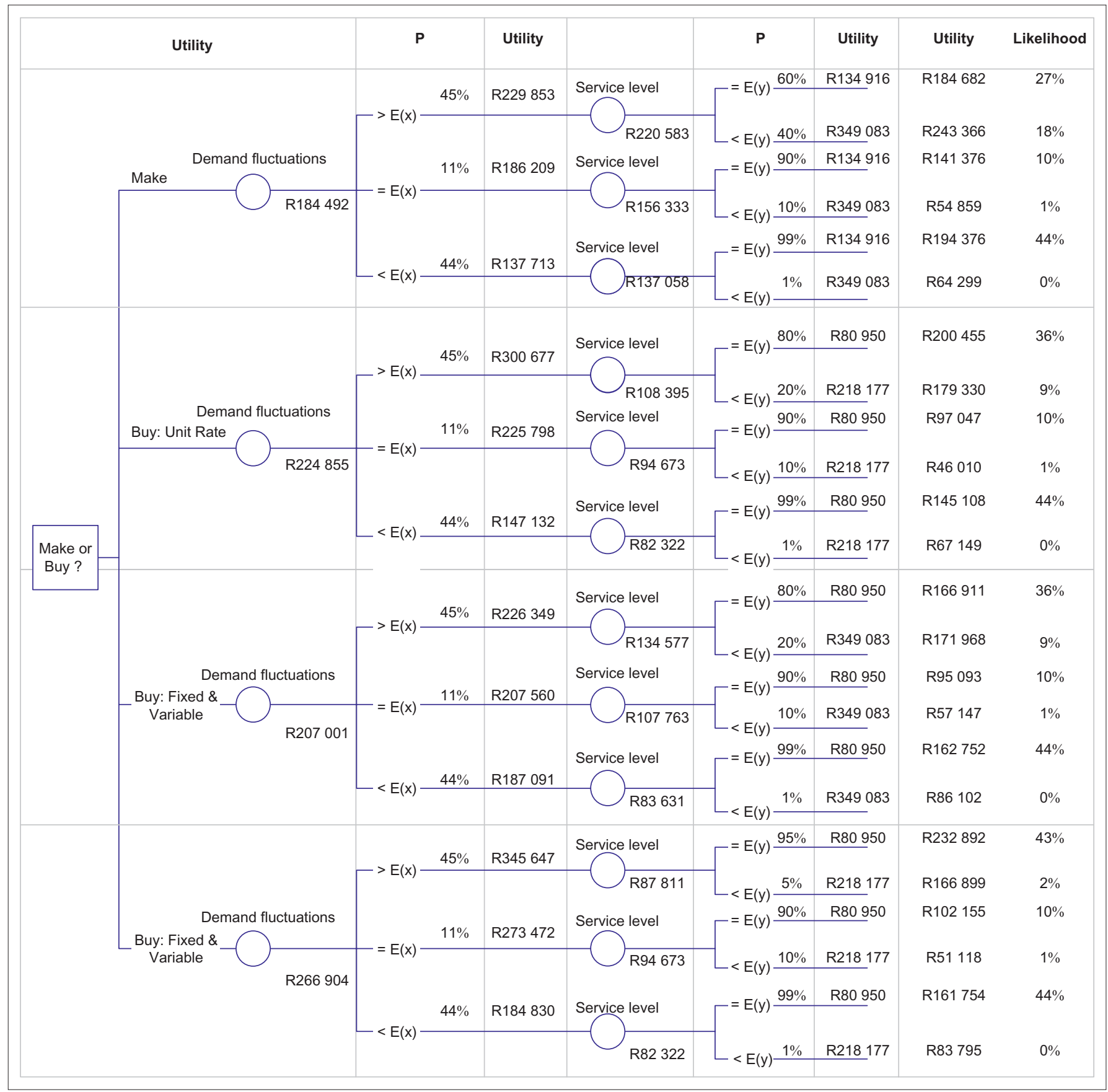

FIGURE 5: Decision tree.

decision and supplier selection problem for each day in the historical data. Each day consisted of a set of variables, such as volume, handling units, number of products and the number of deliveries to be completed. These variables were applied to the various LSP offerings, as discussed in the decision tree section, in order to form the objective function of the model. Certain constraints were imposed on the model and the results were analysed. The mathematical model was built in Excel Solver, which made use of the Evolutionary solving method to complete in excess of a thousand iterations for each daily decision problem. The model produced a preferred service provider per logistics function per day of historical data used as inputs. The daily results data could be aggregated in order to determine which service provider, or in-house option, was the most frequently selected by the LP model.

\section{The decision variables}

The decision variables influence the outcome of the LP model:

$I^{w} \triangleq$ the in-house warehousing option has been selected

where $I^{w} \in \mathrm{I}=\{0,1\}$

$I^{S} \triangleq$ the in-house secondary distribution function has been selected where $I^{S} \in I=\{0,1\}$

$S_{n}^{W} \triangleq$ the warehousing function of a supplier has been selected where $S_{n}^{W} \in \mathrm{I}=\{0,1\}$ 
$n \triangleq\left\{\begin{array}{c}\text { 1LSP with a unit rate contract } \\ \text { 2LSP with a fixed and variable contract } \\ \text { 3LSP with a percentage of sales value contract }\end{array}\right.$

$S_{n}^{S} \triangleq$ the secondary distribution function of a supplier has

been selected where $S_{n}^{S} \in I=\{0,1\}$

Parameters: The parameters are values that represent the in-house cost impact of operating the secondary distribution and warehousing functions and the cost impact of the LSPs operating the secondary distribution and warehousing respectively:

$C^{i s} \triangleq$ the in-house cost of performing the secondary distribution function

$C^{i s} \triangleq$ the in-house cost of performing the warehouse function

$C_{n}^{S} \triangleq$ the cost of LSP $n$ performing the secondary distribution function

$C_{n}^{W} \triangleq$ the cost of LSP $n$ performing the warehousing function

The objective function: The objective of the model is to determine which service provider to select on a daily basis based on the cost impact the service provider would have on that day. The cost impact consists of the sum of the supply charge, driven by the cost model employed, and the opportunity cost lost or loss of sales value as calculated for the decision tree method:

$$
\min \mathrm{z}=\mathrm{I}^{\mathrm{s}}\left(\mathrm{C}^{\mathrm{is}}\right)+\mathrm{I}^{\mathrm{w}}\left(\mathrm{C}^{\mathrm{iw}}\right)+\sum_{\mathrm{n}=1}^{3}\left[\mathrm{~S}_{\mathrm{n}}^{\mathrm{s}}\left(\mathrm{C}_{\mathrm{n}}^{\mathrm{s}}\right)+\mathrm{S}_{\mathrm{n}}^{\mathrm{w}}\left(\mathrm{C}_{\mathrm{n}}^{\mathrm{w}}\right)\right]
$$

The objective to be minimised is the total daily cost impact of using the particular LSP or operating the logistics function in-house. Sole or multiple service providers could be assigned to either the warehousing or the secondary distribution function or both. The in-house option was also compared along with the LSPs. The number of service providers assigned to a logistics function was constrained by Equations 2 and 3.

Constraints: Only one supplier can be allocated the warehousing function:

$\mathrm{I}^{\mathrm{w}}+\mathrm{S}_{1}^{\mathrm{w}}+\mathrm{S}_{2}^{\mathrm{w}}+\mathrm{S}_{3}^{\mathrm{w}}=1$

[Eqn 2]

Only one supplier can be allocated the secondary distribution function:

$\mathrm{I}^{\mathrm{s}}+\mathrm{S}_{1}^{\mathrm{s}}+\mathrm{S}_{2}^{\mathrm{s}}+\mathrm{S}_{3}^{\mathrm{s}}=1$

[Eqn 3]

\section{Research results}

\section{Results from the Platts et al. method}

The method developed by Platts et al. (2000) suggests that insourcing is advisable but that the case study company should focus on improving the technology and process area, which consists of technology advancement and expertise and process capabilities. Technology advancement and expertise can easily be outsourced in isolation to a specialist service provider that focuses on transport management systems and transport planning. On presentation of the results to the case study company, the representatives conceded that secondary distribution planning had only been implemented recently and that managed services or a transport management system was probably the next step in achieving logistics excellence.

The possible sensitivity of the decision to the importance of service levels also proved to be of value to the decision makers. Since the second round of interviews with the executive committee and managers, the in-house service levels have deteriorated and have become a great focus point within the business. Thus, the periodical review of this decision by means of the method developed by Platts et al. (2000) would have highlighted this and indicated that the company should consider outsourcing.

\section{Decision tree results}

The decision tree produces the following results per branch to be taken into consideration when making the logistics outsourcing decision: the maximum utility, which indicates the highest total cost or overall branch utility; the expected logistics costs, the first uncertainty fork's utility; the expected loss of sales, the second uncertainty fork's utility; and the highest likelihood of occurrence that corresponds to the outcome with the highest likelihood per branch. The ranking of these results for each branch from the decision tree should correspond to the company's overall logistics strategy. The branch results are compared and ranked from one to four, where four is the worst ranking (Table 6).

Viewed in isolation, the unit rate and fixed and variable costs model options have the lowest rated utility values, indicating the lowest potential loss of sales and logistics costs combinations. The in-house option is rated the lowest actual logistics costs solution but at a low service level trade-off. The percentage of sales outsourcing option is rated as having the best expected service level value but at the highest expected logistics costs. The highest ranked utility from the highest likelihood branch is associated with the in-house solution, which indicates the risk associated with the low level of expected logistics costs.

These weightings should correspond to the root cause of the change in logistics strategy. For example, should a company decide to pursue outsourcing as a viable option to create value for the end customer by improving service levels, then focusing on reducing loss of sales should be assigned a higher weighting. Four different logistics strategies with the corresponding weightings of each variable were set up (Table 7).

The resultant scores of each option (Table 8) were obtained by multiplying the weighting assigned in Table 7 with the ranked results in Table 6 . Thus, if the decision tree results for a particular branch showed a high overall utility (corresponding to high cost) and the company's strategy is to 
TABLE 6: Comparison of options.

\begin{tabular}{|c|c|c|c|c|}
\hline \multirow[t]{2}{*}{ Branch } & \multicolumn{4}{|c|}{ Decision tree results } \\
\hline & Maximum utility & Maximum expected logistics costs & Maximum expected loss of sales (service level) & Highest likelihood \\
\hline In-house logistics activity & 4 & 1 & 4 & 4 \\
\hline Outsource: $\mathrm{R} / \mathrm{kg}$ cost model & 2 & 3 & 2 & 1 \\
\hline $\begin{array}{l}\text { Outsource: fixed and variable } \\
\text { costs model }\end{array}$ & 1 & 2 & 3 & 3 \\
\hline Outsource: percentage of sales & 3 & 4 & 1 & 2 \\
\hline
\end{tabular}

TABLE 7: Variable weightings per strategy.

\begin{tabular}{|c|c|c|c|c|}
\hline Logistics strategy & Maximum utility (\%) & Maximum logistics costs (\%) & Maximum loss of sales (\%) & Highest likelihood (\%) \\
\hline Higher service levels & 10 & 20 & 60 & 10 \\
\hline Lower logistics costs & 20 & 60 & 10 & 10 \\
\hline Reduced risk & 30 & 30 & 30 & 10 \\
\hline Overall improvement & 25 & 25 & 25 & 25 \\
\hline
\end{tabular}

TABLE 8: Decision tree options.

\begin{tabular}{lccc}
\hline Option & Higher service levels & Lower logistics costs & Reduced risk \\
\hline In-house logistics activity & 4.20 & 2.20 & Overall improvement \\
Outsource: R/kg cost model & 2.30 & 2.50 & 3.10 \\
Outsource: fixed and variable costs model & 3.20 & 2.00 & 2.20 \\
Outsource: percentage of sales & 2.30 & 3.30 & 2.10 \\
\hline
\end{tabular}

reduce costs, the weighting assigned to the maximum utility would penalise the option. Depending on the company's logistics strategy, the best associated option with the lowest score can be selected.

If the company desired higher service levels, then outsourcing with a unit rate or percentage of sales value contract would be favourable. If lower logistics costs and reduced risk were desirable, a fixed and variable costs contract would be favourable. Should the company require an overall improvement, then a unit rate cost structure would be the best fit solution.

\section{Linear programming results}

The LP results were obtained by observing the frequency at which each service provider was selected over a one-year period and analysing these results along with trends in the historical data, such as seasonal volume fluctuations and distribution network changes. Correlations can be drawn as to which service provider or outsourcing option is preferable under different circumstances.

Observations of the results show that the in-house option was selected to perform the secondary distribution function $87 \%$ of the days in the historical data; the supplier with the percentage of sales value contract was selected $7 \%$ of the days and the unit rate contract was selected $6 \%$ of the days. The in-house cost of performing the secondary distribution function and the historical in-house performance resulted in the lowest cost option in the case of the secondary distribution function.

In the case of the warehousing function, the LSP with the percentage of sales value contract was selected $50 \%$ of the days. It was prevalently selected during the first six month of the year, whereas the LSP with the fixed and variable costs model was selected $43 \%$ of the days and prevalently towards the latter six months of the year. On further inspection, the standard deviation of the design variables increased towards the end of the historical period under review, which translates to larger demand volatility which affects the LSP's ability to provide high service levels and minimise costs. The LSP with the fixed and variable costs model performed best during this period.

\section{Evaluation of results}

The decision-making method used to aid management in making the logistics outsourcing decision should ideally address evaluation criteria such as logistics costs, the associated risk, long-term strategy (McIvor \& Humphreys 2000), service provider fit, the degree of market growth achieved and service levels (Razzaque \& Sheng 1998). In this case study, these factors were used to compare the methods applied to the logistics outsourcing decision problem.

\section{Logistics costs}

All the decision-making methods take logistics costs into consideration. The method developed by Platts et al. (2000) assigns a rating to the expected in-house logistics costs as well as to the expected LSP cost. Although this method of cost comparison is probably the most frequently adopted in the industry, it does not take into consideration demand variability and the risk associated with dealing with consumer spending behaviour. Using the decision tree method, the decision maker is forced to analyse the demand fluctuations, assign a probability to the less favourable outcome and produce an associated cost, which highlights the risk associated with decisions. LP offers a detailed approach that focuses on minimising the logistics 
costs impact on a granular level. The effect of fluctuating demand on costs and sales is quantified in the case of the LP method.

\section{Associated risk}

Although the method developed by Platts et al. (2000) gives an indication of the sensitivity of a decision to certain factors, it does not associate a cost or utility to the sensitivity or risk that the decision maker faces. The decision maker has no frame of reference as to the size of the risk when looking at the gap between the break-even point on the sensitivity graph and the associated weighting of the area. Biased decision-making comes into play here, as the information is aggregated to such an extent that it is taken out of context and the decision maker will either overestimate or underestimate the representativeness of the information and will draw inaccurate conclusions from it. In comparison, the LP method creates visibility of daily changes in LSP preference, which can be analysed together with market demand changes and future product promotions to select the LSP which best suits the company's marketing strategy. The decision tree method highlights the risk faced in each outcome by adequately assigning a probability derived from sound statistical analysis.

\section{Long-term strategy}

All methods take the company's logistics strategy into account by placing more emphasis on certain decision variables than others. The method developed by Platts et al. (2000) provides a quick method of checking whether the decision is viable by changing the weightings and ratings assigned to the decision variables, whereas updating and changing the decision tree and LP models will require a new statistical analysis of the latest available data. The decision tree and LP models can be adapted to run various what-if scenarios. By changing the historical data used to portray different scenarios in the future, such as massive demand fluctuations or increased volumes due to new product launches, the decision makers can extend the period under review and take the strategic direction of the company into account.

\section{Service provider fit}

The cost model used in logistics arrangements has a big impact on the service provider and customer behaviour. Integrated vendors will apply shared resources to the most profitable customer. Customers of LSPs using the fixed and variable costs model would require the LSP to reduce costs, whilst dedicating resources and upholding service levels. Customers are also often surprised when additional costs are incurred due to labour strikes and demand-related resource requirements when using a fixed and variable costs model. The main cause of this is the fact that the expected cost is used when comparing LSPs.

The method developed by Platts et al. (2000) only assigns a rating to the service provider based on their expected cost relative to each other and the expected in-house cost. The decision tree and LP methods expose the actual cost impact of fluctuating demand and service levels by applying the in-house cost of performing the operation or the LSP rate to the daily demand activity. Hence, decision makers can understand exactly what will happen should market volatility increase.

Service provider fit should include a cultural aspect as well as a technology advancement component. These items are easily worked into the method developed by Platts et al. (2000) but will require an additional step to be added to the decision tree and LP models to compare service providers on an observed level of cultural fit and technological advancement, such as the use of fuzzy logic proposed by Guneri et al. (2009).

\section{Degree of market growth achieved}

The degree of market growth can be modelled using the decision tree and LP methods by extending the expected service levels to above $100 \%$. This means that the existing customer base is extended. The market growth can be added to the method developed by Platts et al. (2000) by contacting the service provider references and obtaining the market growth achieved in the case of the reference, and assuming that the same relative level of growth is possible if the reference were not a new company.

\section{Service levels}

All methods address service levels adequately. Again, the decision tree method exposes and quantifies all the risks and rewards associated in more detail than the method developed by Platts et al. (2000), and the LP method requires the decision makers to identify correlations and trends within the results to expose potential risks.

\section{Conclusion and recommendations}

The complexity faced by logistics professionals when making decisions such as the make-or-buy and supplier selection decisions creates a need for a sound decision-making method that ensures that all information presented is clear, is viewed in the broader scope of strategy and incorporates the right evaluation criteria. This paper provides empirical evidence that proven make-or-buy decisions can be applied in a logistics outsourcing context. Furthermore, the paper provides tactical decision makers with three examples of the application of proven decision-making methods in a South African logistics outsourcing context. Each method is associated with a certain level of detail and the decision maker can select the appropriate method based on the information and resources available.

In the case of the case study company, the method developed by Platts et al. (2000) indicates that the logistics services should stay in-house. Based on the logistics strategy of the company to produce high service levels at sustainable cost, the decision tree method suggests that the answer lies between the two strategies: higher service levels and low logistics costs. The average score between the two strategies suggests logistics outsourcing with a unit rate contract. The 
LP method offers the decision makers the opportunity to select an LSP per logistics function under consideration, without additional complex calculations. In the case of the secondary distribution function, an in-house operation is proposed, and in the case of the warehousing function, the decision maker needs to determine whether the change in demand volatility is a seasonal occurrence or whether the market has changed. Then, either the LSP with the percentage of sales value cost model or fixed and variable costs model should be selected.

Although the method developed by Platts et al. (2000) produces a quick definitive answer, the decision tree method creates a more detailed view of the decision problem that the company faces as the upside and downside of options are highlighted and the decision maker has an idea of the probability and associated risk of each option. The LP method creates the opportunity for the decision maker to choose an LSP per function without overcomplicating the decisionmaking process. The LP and decision tree methods are flexible, and can accommodate changing market conditions, projected values and perceived risk for scenario modelling purposes. Future changes or a longer-term strategic view can be incorporated into these two methods. A regression analysis can be performed using the historical data to produce a forecast of the logistics activities required and then applying the proven decision making methods to the forecast. All probabilities and cost impacts are determined by scientific and statistical inference based on actual historical figures.

The use of the decision tree method is proposed, as it has the advantage of displaying the decision problem in a compact form from which the decision maker can compare all the information simultaneously. The decision maker is allowed to explore the detail of all possible alternatives.

The study provides empirical evidence that proven outsourcing decision-making methods, such as the method developed by Platts et al. (2000), the LP method and the decision tree method traditionally applied to a manufacturing outsourcing decision problem, can be adapted and applied to a logistics outsourcing decision problem of a South African FMCG company. The methods successfully used the information that was available to the company in practice, dependent on scientific and statistical inference. Moreover, they did not rely on a repository of LSP performance history built up over years of experience in dealing with such LSPs, as this would be a costly process. All methods could incorporate the required evaluation criteria and decisionmaking objectives.

This study is limited to the implications of normal operational fluctuations due to demand volatility. Special causes of variation such as labour strikes, fuel and electricity hikes and the impact of legislation have not been taken into account. Furthermore, only one case in the context of South African logistics outsourcing was tested, with a relatively average level of complexity. Factors contributing to the complexity of a case study include network, product and process complexities (Rao \& Young 1994). Network complexities refer to complexities associated with multiple trading partners, countries and continents. Product complexities refer to complications that arise from product characteristics such as size, density and environmental requirements (storing temperatures etc.) which affect the handling of the product. Process complexities relate to time sensitivity, manufacturing cycle times and order cycle times of the product within the supply cycle.

It is recommended that a more complex case study be tested which incorporates different combinations of product, process and network complexities. The application of the proven decision making methods in a more complex context will determine the extent to which these methods can be applied in a logistics context and provide a more detailed definition of the limitations of these methods. It is further recommended that the service provider's decision problem be formulated and that the proven decision making methods be applied in this context.

\section{Acknowledgements Competing interests}

The authors declare that they have no financial or personal relationships which may have inappropriately influenced them in writing this article.

\section{Authors' contributions}

N.B. (Clover Industries Limited) contributed to the concept and design of the study as well as the collection and analyses of the data. She performed the interpretation of the analysis results and drafted the article. W.L.B. (University of Pretoria) contributed by providing focus and guidance to the study, revising the article critically, ensuring that all content was relevant and approving the final version of the article.

\section{References}

Arvelos, P.A., 2014, When to make or buy? A framework for make-or-buy decision making, Instituto Poltécnico de Setùbal, Setùbal.

Fitzgerald, J.A., 2007, 'Six essential strategies for selecting a global 3PL', Inbound Logistics, viewed October 28 April 2015, from http://www.inboundlogistics.com/ $\mathrm{cms} /$ article/six-essential-strategies-for-selecting-a-global-3pl/

Gadde, L.E. \& Hulthén, K., 2009, 'Improving logistics outsourcing through increasing buyer-provider interaction', Industrial Marketing Management 38(6), 633-640. http://dx.doi.org/10.1016/j.indmarman.2009.05.010

Guneri, A.F., Yucel, A. \& Ayyildiz, G., 2009, 'An integrated fuzzy-LP approach for a supplier selection problem in supply chain management', Expert Systems with Applications 36(10), 9223-9228. http://dx.doi.org/10.1016/j.eswa.2008.12.021

Hsiao, H.I., Van der Vorst, J.G.A.J., Kemp, R.G.M. \& Omta, S.W.F., 2010, 'Developing a decision-making framework for levels of logistics outsourcing in food supply chain networks', International Journal of Physical Distribution \& Logistics Management 40(5), 396-414. http://dx.doi.org/10.1108/09600031011052840

Mclvor, R.T. \& Humphreys, P.K., 2000, 'A case based reasoning approach to the make or buy decision', Integrated Manufacturing Systems 11(5), 295-310. http://dx.doi. org/10.1108/09576060010335573

Moschuris, S.J., 2008, 'Organizational participants in the make-or-buy process', Industrial Marketing Management 37(2), 143-153. http://dx.doi.org/10.1016/j. indmarman.2006.11.002

Moses, A. \& Åhlström, P., 2008, 'Dimensions of change in make or buy decision processes', Strategic Outsourcing 1(3), 230-251. http://dx.doi. org/10.1108/17538290810915290

Platts, K.W., Probert, D.R. \& Canez, L., 2000, 'Make vs buy decisions: A process incorporating multi attribute decision making', International Journal of Production Economics 77, 247-257. http://dx.doi.org/10.1016/S0925-5273(00)00177-8 
Rahman, S., 2011, 'An exploratory study of outsourcing 3PL services: An Australian perspective', Benchmarking 18(3), 342-358. http://dx.doi.org/10.1108/14635771 111153527

Rao, K. \& Young, R.R., 1994, 'Global supply chains: Factors influencing outsourcing of logistics functions', International Journal of Physical Distribution \& Logistics Management 24(6), 11-19. http://dx.doi.org/10.1108/09600039410066141

Razzaque, M.A. \& Sheng, C.C., 1998, 'Outsourcing of logistics functions: A literature survey', International Journal of Physical Distribution and Logistics Management 28(2), 89-107. http://dx.doi.org/10.1108/09600039810221667

Ruiz-Torres, A.J. \& Mahmoodi, F., 2007, 'The optimal number of suppliers considering the costs of individual supplier failures', Omega 35(1), 104-115. http://dx.doi. org/10.1016/j.omega.2005.04.005
Sangam, V., 2013, 'Logistics outsourcing trends - 2013', Supply Chain World, viewed 02 June 2004, from http://vijaysangamworld.wordpress.com/2013/07/17/ logistics-outsourcing-trends-2013/

Savage, S.L., 2003, Decision making with insight, Brooks/Cole Thomson, Belmont.

Statistics South Africa, 2014, Indicators, viewed 01 March 2014, from http://beta2. statssa.gov.za/?page_id=593

Wan, S.-P., Wang, F., Lin, L.-L. \& Dong, J.-Y., 2015, 'An intuitionistic fuzzy linear programming method for logistics outsourcing provider selection', Knowledge-Based Systems 2(27), 1-15. http://dx.doi.org/10.1016/j.knosys.2015. 02.027

Winston, W.L., 2004, Operations research, 4th edn., Thomson, Belmont. 